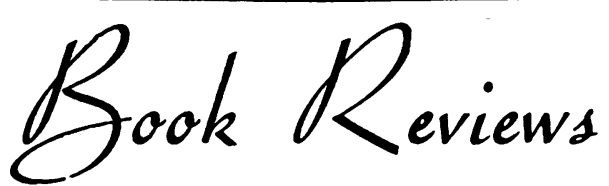

\section{LEUKOCYTE ANTIGENS AND ANTIBODIES}

By Roy L. Walford, M.D. Pp. ix +182 . New York and London: Grune and Stratton Inc. 1960 . $\$ 6.75$.

Professor Walford deals in this book with a difficult subject made familiar to him by extensive personal experience. The book is timely in that whilst knowledge of leukocyte antigens and antibodies has been rapidly accumulating this is the first English monograph on the subject. The book may be considered in two parts, the first being a useful summary of methods. The author gives full details and mentions the pitfalls of these notoriously difficult techniques. The remainder of the book deals with interpretation of information on the antigenicity of leucocytes. This part is necessarily speculative but remains valuable. This book will interest research workers and medical practitioners of many specialities. As a comprehensive monograph it will be welcome to workers in this narrow field.

\section{TEXTBOOK OF SURGICAL PATHOLOGY}

By C. F. W. Illingworth, C.B.E., M.D., Ch.M., F.R.C.S. (Ed.), F.R.F.P.S.(Glas.), and BRUCE M. DICK, M.B., F.R.C.S.(Ed.), F.R.F.P.S.(Glas.). Eighth Edition. Pp. viii +704 ; figs. 329 . London. J. \& A. Churchill Ltd., 1960. 75 s.

'Illingworth and Dick' has been a staunch friend of surgeons for nearly 30 years and it is a pleasure to welcome it in its new (eighth) edition. Its approach to the surgical pathology is thoroughly up-to-date and there is a refreshing emphasis on disorders of function (both physiological and biochemical) as well as of structure. The pathological basis of the clinical features of surgical disease is stressed throughout. The authors do not hesitate to point out where knowledge is lacking.

The subject matter includes all that one could hope for in 1960 . There are, for instance, chapters on the constitutional effects of injury and on the transplantation and preservation of tissues, and there are discussions of topical subjects such as hypothermia, the endocrine aspects of breast cancer, post-gastrectomy syndromes, the pathological effects of operations for portal hypertension, nuclear sexing, the effects of vagotomy on hypertrophic pulmonary osteo-arthropathy, auto-immune disease, ulcer-producing tumours of the pancreatic islet cells, intestinal cul-de-sac phenomena, argentaffinomatosis, and so on.

The style is lucid and succinct. The lay-out, printing and illustrations are clear, the index is adequate, the binding is good and the price is reasonable. The Fellowship candidate who know all that is in this book will have mastered three quarters of the theoretical requirements of the examination. The practising surgeon who has it on his bookshelf will take it down frequently and find much profit in it.

\section{NITROUS OXIDE IN DENTISTRY. ITS DANGERS AND ALTERNATIVES}

By J. G. Bourne, M.A., M.D. (Cantab. F.F.A.R.C.S. Pp. $x+181$. Illustrated. Lono don: Lloyd-Luke (Medical Books) Ltd. 1960 30 s.

It is a measure of Dr. Bourne's originality and pertinacity that his chance observation that faintin during the induction of nitrqus oxide anaesthesia in the dental chair might be both the reason for an unexpectedly. easy anaesthetic and the simulf taneous cause of cerebral hypoxia and subsequen? brain damage has developed into a scientifio investigation, the details of which are described in this excellent book. Dr. Bourne brings refresh ingly new ideas to the problem of general anłes thesia in dentistry, maintaining an entirely objective approach to the evaluation of a large amoun of original experimental and clinical data, and not failing to draw some very pertinent clinical cont clusions-conclusions that remind us all that minof surgery is not necessarily synonymous with mino anaesthesia.

This book reports far more than an investigatio of nitrous oxide, for it contains an exceptionall good description of the pharmacological an physiological mechanisms involved in the uptake and elimination of inhalational anaesthetic agents coupled with a wise discussion of their relative safety in terms of volatility, potency, and speed of uptake. Sections such as this, and another on the. evolution of the muscles that control the larynx and its relationship to laryngeal spasm during anaes thesia with thiobarbiturates, cannot be bettere and should make standard reading for all anaes thetists. Ignorance of the importance of such basit data has led to more misunderstanding of the true dangers of anaesthetic drugs than almost any otheo factor in anaesthesia.

This is not a book to be delved into-not, least, in the first place-since the text follows of logical train of thought and argument. It should be read through to be best appreciated. Indeed any doctor, once having started, is unlikely to put it down until completed. He will be fascinated $\mathrm{b} \$$ the curiosity it evokes, and delighted by the prose in which it is written. 